\title{
Development and Reflection of Chinese Government Micro-Blog from the Perspective of Public Administration
}

\author{
Meng Ying
}

School of Journalism and Communication, China University of Political Science and Law, Beijing, China

\begin{abstract}
This paper regards the government micro-blog as research object, discuss their daily published content, communication effects, especially their response model about crisis events and the influence of public opinion. Analysis on the innovation in government public management mode, development trend and existing problems of government micro-blog. Have important implications for social management and the transform of the public security and the court in the new media age.
\end{abstract}

Keywords - new public management, government micro-blog, public security and the court transform, service-oriented government

\section{公共管理视角下我国政务微博的发展与反思}

\author{
孟盈 \\ 中国政法大学新闻与传播学院, 北京, 中国
}

摘 要 以政务微博为研究对象, 对其发布的内容、传播效果, 特别是危机事件中政务微博的反应模式和與论影响进行探讨, 分析 政务微博在政府公共管理模式上的创新、发展和存在的问题，对新媒体时代我国政府的公法变革、社会管理有重要启示作用。

关键词 新公共管理，政务微博，公法变革，服务型政府

新公共管理理论滥解于上世纪八十年代, 发展至今日 其内容还在不断发展中, 众多国家和政府都对它不断加以 探讨，实践。新公管理论主张政府公共管理应由服务效率 优先转向服务品质优先，同时自上而下的政府控制应转向 争取社会成员对政府工作绩效、工作价值的认同。新公管 理论的发展可以说是与新媒体发展相辅相成的, 一方面新 媒体发展、网络社会的发展改变了政府工作的环境、公众 对政府职能的期待, 对政府的公共治理能力提出考验, 敦 促政府更快更好的完成服务型政府和电子政府的改革; 另 一方面, 新媒体平台的建立为政府变革指明方向, 为实现 电子政务、提升公共服务品质提供方法和条件。在此背景 下诞生的政务微博可以说是我国政府机关对此现实需求的 有效回应。

政务微博包括党政机构微博和党政干部微博, 党政机 构微博客是指各级党委、人大、政府、政协、纪委、人民 法院、人民检察院及其工作部门和机关内设机构, 以及其 他参照公务员法管理的人民团体和事业单位开通的实名认

本研究受中国政法大学青年教师学术创新团队项目资助
证微博客; 党政干部微博是在上述机构工作的干部开通的 实名认证微博。我国政务微博诞生的标志是 2009 年湖南桃 源县官方微博“桃源网”的开通, 中共云南省委宣传部的“微 博云南”紧随其后, 继而, 一大批党政机关、领导的微博迅 速开通, 特别是在政府变革中一直持保守态度的公法机构 在这过程中表现突出, 来自公法机构、官员个人的微博在 数量和范围上都呈现持续、快速增长势头。经过不断探索, 政务微博已经在政府信息公开、信息沟通和信息服务、與 论引导等方面承担起政府公共管理的事务, 成为新媒体时 期政府公共管理的重要平台。

\section{1. 政务微博创新公共服务模式}

政务微博与政府原有的公共服务模式不同, 它对公共 服务模式的创新体现在以下方面:

\section{1 从渠道到平台一一重视新媒体渠道、建设新媒体平台} 政务微博基于微博这个與论场，不同于传统的政府服

\footnotetext{
1 国家行政学院, 2012 年中国政务微博客评估报告, http://www.egovernment.gov.cn
} 
务网站和问政网站。微博的准入门槛低, 能够更直接、有 效、平等的与民众展开互动, 进行政民交流, 面向更广泛 的大众群体, 符合新媒体时代传播特点和游戏规则。特别 是以前只依靠少量传统媒体渠道发布信息, 甚少与公众沟 通的公、法机构, 在抢滩微博舆论场中的表现尤为突出。 根据正义网络传媒研究院的统计, 截至 2013 年 12 月 20 日, 全国公安、检察、法院、司法行政四类政法机关和公职人 员, 在各大微博平台开通的官方微博总计已达 3.75 万个。在 政务微博蓬勃发展的背后是政府新闻宣传体制、與情应对 机制的改革, 体现了政府对新媒体渠道的重视, 以及建设 新媒体平台、加大與论引导力量的决心。

1.2 从内容到方式——创新政府公共服务范围、扩大政府 公共服务功能

在政务微博中, 表现最抢眼、具有较高的关注度和影 响力的是公安微博。以新浪政务微博为例, 公安系统的微 博占据政务微博总数的三分之一多, 如“公安部打四黑除四 害”、“平安北京”、“广州公安”、“平安中原”、“警民直通车 —上海” 等都是这方面的典型代表。这些政务微博获得高 人气的关键就是其从传播内容到传播方式上的创新。传统 的政务沟通内容只局限于信息传达、新闻宣传, 而政务微 博的传播内容不断扩大, 演变成一个综合信息服务平台, 并走向系统的微博问政, 各级政法机关通过微博收集网络 民意、回应公众诉求、受理信访举报的例子不胜枚举。以 新浪公安微博“平安北京”为例, 除了提供传统的案例报道、 公安活动介绍、先进人物宣传等信息外, 更开通了与居民 生活息息相关的多个服务栏目, 比如“安全课”（提醒居民 日常生活中可能引发安全事故的诱因, 并针对此介绍防范 措施）、“天气预报”（向北京市民提供当日的气象信息、汽 车当日限号等)、“出行提示” (第一时间提供北京市最新路 况信息及出行提示) 等栏目。此外, 在信息沟通方面“平安 北京”开通了“平安北京直播间”栏目。在栏目选题设置中, 引入网友意见和建议征求机制, 组织网友对备选选题进行 公开投票, 根据结果组织策划活动, 实现“我说什么您做 主”; 改变以往网上互动的单一模式, 将现场互动与网上互 动结合起来, 如在预防煤气中毒宣传中, 实时报道社区民 警入户检查, 穿插介绍防范知识。

\section{3 由效率到品质——提升政府公共服务能力的轻骑兵}

政务微博作为信息服务平台能够缩减政府公共服务的 程序, 公开、透明的网络环境能够敦促政府提升公共服务 绩效和服务品质, 推动政府从等待事件发生到主动寻找问 题, 解决问题转变。特别在危机事件中, 政务微博和传统 媒体的联动使政府迅速获知信息, 传达政策, 掌握危机事
件中的主动权, 大大提升了政府公共服务的能力和效率, 例如雅安地震中, 四川本地的政务微博通过及时、快速、 全面的灾情、物资、援助的信息发布, 聚合举国能量, 捍 卫灾区生命线。

另外, 政务微博在发布形式上也积极运用网络语言, 体现出人格化、口语化、务实、亲民的特点, 为政府公共 服务增加暖度。特别是人们传统思维中与亲和扯不上关系 的公安、司法机关, 通过微博走进百姓生活, 重塑社会形 象, 加强了公、法机关的认同感和公信力。这些创新扩大 了政府公共服务的内容和范围, 大大增强了政府公共服务 功能, 同时也是新时期我党群众路线与时俱进的体现。

\section{2. 从主体变革到观念变革一一政务微博发展中的短 板}

政务微博作为一种新媒体, 为民众提供了一个更加便 捷、开放和多元化的平台, 增强了民众的话语权, 在政府 公共服务中的力量日益凸显, 然而它同时也是一柄双刃剑。 声音多样化、信息源多元化以及社会问题本身的复杂多变, 也使政府公共服务的难度加大。2在发展过程中, 政务微博 难免出现一些不规范的地方, 体现出“空心化、形式化、名 利化”的短板 3 , 以新浪微博 14 年 2 月采集的数据为例, 在 法院微博中，发布数量最多的“公正肇庆”与数量最少的“沈 阳中院”之间的数量差距达 460 多倍。在公安微博中, 这一 比例约为 42 倍。究其根本还是观念的问题。

\section{1 改变心态, 下到服务“第一线”}

政务微博的兴起实际上是一种新型民主形式创新, 要 求政务机关人员改变原来高高在上的心态, 下到服务“第一 线” 的位置; 改变应对危机事件时 “重态度、重表彰、避言 原因、慎言结论、最后报进展” 的传统工作思路, 适应网络 传播环境和传播特点, 积极回应, 快速处理, 透明公正, 在第一时间化解危机, 引导舆论。2011 年南京出台《关于 进一步加强政务微博建设的意见》, 意见中明确规定: 对于 灾害性、突发性事件, 要在事发一小时内或获取信息的一 小时内进行微博发布。只有这样才能被这个传播环境所认 可。

\section{2 真诚、公正、平等、高效}

面临突发事件时, 由于少数媒体记者或网民的出位,

\footnotetext{
2 张蓉 郑克强, 试论微博在创新社会管理中的作用, 江西社会科 学, 2011 (10)

3 冯荣刚, 熊小刚, 新媒体语境下政府部门公共服务模式的挑战 与创新——以政务微博为例.江西农业大学学报 (社会科学版), 2013 (3) :127-131
} 
哗众取宠, 个别媒体片面不实的报道对政法机关的正面形 象产生巨大的破坏力。此时, 政务微博的回应稍有不慎就 会成为新一轮民愤的激发点, 致使谣言和猜测泛滥成灾, 造成不可逆转的恶劣影响。因此, 只有尽可能发布全面、 权威的信息, 并且态度真诚, 才能在與论引导中发挥其正 面作用。

\section{3 以人为本, 体现人文关怀}

政法宣传工作在开展工作、满足公众知情权的同时, 应该注意体现一定的人文关怀, 不能端架子, 也不能哗众 取宠。应对突发事件时, 更应该谨慎, 选好角度, 充分体 现对当事人基本权利的尊重和对社会主义法治权威的维 护。在及时回应社会关切的问题, 尽最大努力解决民众的 合理诉求, 避免谣言扩散, 掌握與论主动权, 最大限度地 化解或减少危机带来的负面影响, 从而有效应对突发事件。 正如习近平在中央网络安全和信息化领导小组第一次会议 中指出的, 做好网上與论工作是一项长期任务, 要创新改 进网络宣传, 运用网络传播规律, 弘扬主旋律, 激发正能 量, 大力培育和践行社会主义核心价值观, 把握好网上與 论引导的时、度、效, 使网络空间明朗起来。

\section{3. 政务微博的管理与发展}

\section{1 实现政府权利下授至“沟通第一线”}

政府从管理型到服务型变革的关键是权利的下授。政 务微博作为政府民众的沟通第一线相当于多元化、全方位 的民众触点, 如同一个全功能的柜台, 通过政务微博实现 多种形式的权利下授, 可以帮助政府更快更好的完成公共 事务处理, 探查民意, 建立“顾客”关系。因此, 发展政务 微博也应注意系统推进政府新闻宣传体制的整体改革, 加 强各部门, 特别是加强公、法系统对新闻宣传工作的认识 和力度, 提高整体媒介素养, 明确责任, 建立专业微博运 营团队, 切实把权利下授, 重视公共事件的解决方法和治 理效果。

\section{2 深化创新、整合服务}

政务微博作为政府电子政务的一部分, 深化创新和服 务整合是关键。一方面是打通纵向链条, 以微博微基础建 设全媒体平台, 通过和媒体互动, 利用各种终端, 实现网 络问政的全面覆盖; 一方面是横向联合, 通过大型政务微 博群实现区域“集团效应”。例如上海市政府就是这方面典 型。上海市政府的官方微博—上海发布组成微博矩阵, 包括“警民直通车一上海”、“上海发展改革”、“上海商务”、 “上海教育”等市级委办局微博五十个; “浦东发布”、“上海
黄浦”、“上海静安”等区县政府微博 17 个; “上海工会发布”、 “上海供水”等主要社会群众团体、公共服务机构、国有企 业微博 15 个。在“上海发布”的统领下, 政府机构及官员均 开设微博, 官员的参与度普遍比较高, 公、法系统微博活 跃度高, 在微博平台上打通了不同政府机关之间㖶化的行 政壁垒, 促成机构间的合纵连横, 大大降低行政成本、交 流成本和信息损耗, 提高了政府的工作效率, 能够更好的 统筹调配社会资源, 最大程度利用人力、财力、物力。

\section{3 加强政务微博绩效评估与监督}

政务微博的长效发展还需要加强绩效评估, 进一步建 章建制, 包括政务微博信息发布的审核、信息内容的规范、 信息服务范围的确定和网上办事流程的建立。优质政务微 博要求专业的微博管理团队, 使微博管理常态化、科学化。 在考核中还可考虑将政务微博服务效果纳入政府机构部门 绩效考核中, 加大政府机关对其的重视度。另外, 政务微 博还需主动倾听民众的声音, 需要有相对独立的第三方对 其进行监督。

当前, 创新政府公共管理已经成为从中央到地方的共 识, 作为政府公共治理的新平台, 政务微博在短短几年内 已成为“官民对话沟通的喧器广场”、“化解分歧、弥合裂痕 的桥梁”, 成为“修复公信、凝聚民心的粘合剂”、“新时期贯 彻我党群众路线的一线阵地”。“政务微博发展任重而道远, 它不止是政府信息公开的一部分, 还承担着民主政治建设、 引导社会與论、建构意识形态的任务, 对推动公、法变革, 建构政府公共服务模式有重要作用。

\section{参考文献(References)}

[1] M. Young, The Technical Writer's Handbook. Mill Valley, CA: University Science, 2011.

[2] Lu Kunjian and Miao Yuexia, the Theory and Practice of Responsive Government, 2011.

\footnotetext{
4 人民网舆情监测室, 2011 年微博政民互动典型案例分析报告, http://media.people.com.cn/GB/40606/15508240.html
} 